Criar Educação, Criciúma, v. 9, n 3, ago/dez. 2020 - PPGE - UNESC - ISSN 2317-2452

\title{
A APROPRIAÇÃO DA ESCRITA ACADÊMICA: UMA ANÁLISE A PARTIR DE CURRÍCULOS DE CURSOS DE GRADUAÇÃO
}

\author{
Richarles Souza de Carvalho ${ }^{1}$
}

Tânia Machado Zanette Cardoso²

\begin{abstract}
Resumo: Diante da fragilidade das habilidades de leitura e escrita acadêmica na educação superior, faz-se necessário desenvolver reflexões acerca do letramento em cursos de graduação. O presente estudo tem como intuito problematizar dificuldades de discentes referentes à escrita acadêmica. Objetiva também aferir a oferta e frequência de disciplinas que tratam da produção e interpretação de textos acadêmicos em cursos de universidades não públicas do estado de Santa Catarina. A metodologia envolve procedimento bibliográfico e documental, de abordagem qualitativa. A análise demonstra que a oferta de tais disciplinas ainda é tímida. É importante investir em meios de qualificar a aprendizagem de escrita acadêmica, disponibilizando mais disciplinas nos currículos e a utilização de metodologias interdisciplinares.
\end{abstract}

Palavras-chave: Letramento. Ensino Superior. Escrita Acadêmica.

\section{THE APPROPRIATION OF ACADEMIC WRITING: AN ANALYSIS FROM UNIVERSITY GRADUATE}

\begin{abstract}
Faced with the fragility of academic reading and writing skills in higher education, it is necessary to research literacy in undergraduate courses. This study aims at problematizing the difficulties of students regarding academic writing. It also aims at analyzing the offer and frequency of subjects related to reading and writing academic texts in undergraduate courses of non-public universities in the state of Santa Catarina. The methodology involves bibliographical and documental procedures, of qualitative approach. The analysis demonstrates that there is a fragile offer of such discipline. It is important to invest in ways of qualifying academic writing, providing more disciplines and the use of interdisciplinary methodologies.
\end{abstract}

Keywords: Literacy. Higher Education. Academic writing.

\footnotetext{
1 Doutor em Ciências da Linguagem pela UNISUL (Universidade do Sul de Santa Catarina). Docente na área das Humanidades na UNESC (Universidade do Extremo Sul Catarinense). E-mail: rsc@unesc.net

2 Especialista em Docência no Ensino Superior pela UNESC (Universidade do Extremo Sul Catarinense). Professora da rede estadual de educação de Santa Catarina. E-mail: taniamzanette@bol.com.br
} 
Criar Educação, Criciúma, v. 9, nº 3, ago/dez. 2020 - PPGE - UNESC - ISSN 2317-2452

\section{INTRODUÇÃO}

Considerado como obstáculo por grande parte dos ingressantes no ensino superior, a produção de textos permeia o cotidiano acadêmico ao longo de todo e qualquer curso. Para muitos, há uma enorme complexidade em organizar um texto de qualidade, e colocar as ideias no papel torna-se um entrave. Alguns aspectos contribuem para agravar esse cenário, sendo um dos principais a dificuldade de interpretação que, decorrente de uma leitura rasa, ocasiona um rendimento insuficiente nas produções escritas. Geraldi (2006, p. 39) ressalta que "ocupa lugar privilegiado o baixo nível de desempenho lingüístico (sic) demonstrado por estudantes na utilização da língua, quer na modalidade oral, quer na modalidade escrita". Considerando que a escrita é caracterizada como uma prática social, defendida por vários autores, é importante por em pauta que a diversidade social interfere nas formas de escrever.

De fato, a produção textual constitui-se requisito primordial nos cursos de graduação. Todavia, observa-se um letramento deficiente no contexto do ensino superior, no que tange às habilidades de leitura e escrita. Nesta última podem ser considerados aspectos problemáticos de coesão e coerência, bem como um vocabulário limitado que emerge das produções. Algumas dessas dificuldades são atribuídas à defasagem da escolarização básica, que resulta em um quadro precário em termos de proficiência e performance nas produções escritas. Geraldi (2006, p. 39) enfatiza que "é necessário reconhecer um fracasso da escola e, no interior desta, do ensino de língua portuguesa tal como vem sendo praticado na quase totalidade de nossas aulas".

A obra de Geraldi foi lançada na década de 1980, mas ainda se apresenta contemporânea e relevante no presente contexto educacional. E apesar de 0 texto ser direcionado à Educação Básica, alguns reflexos são percebidos na Educação Superior, justamente pelo modo como se dá o ensino de língua portuguesa na escola, abordado pelo autor. Esse modo de ensino é responsável pelo know-how que os acadêmicos demonstram ao ingressar na universidade. 
Criar Educação, Criciúma, v. 9, № 3, ago/dez. 2020 - PPGE - UNESC - ISSN 2317-2452

Diante do exposto, faz-se importante refletir sobre o papel que assume a disciplina de Produção e Interpretação de Textos - $\mathrm{PIT}^{3}$, ou disciplinas correspondentes, em cursos de graduação, bem como sua contribuição para o avanço do letramento acadêmico, considerando os processos de ensinoaprendizagem relevantes para esse contexto.

Apresentando uma metodologia que dispõe de procedimento bibliográfico e documental, com abordagem qualitativa, o presente artigo tem por finalidade identificar os desafios do processo ensino-aprendizagem que permeiam o letramento na graduação, compreendendo as exigências para 0 desenvolvimento das habilidades de leitura e escrita de qualidade. Sendo a universidade o lugar mais propício para o ensino e desenvolvimento da escrita acadêmica, este estudo objetiva também, demonstrar a oferta de disciplinas que desenvolvem escrita e leitura, em diversas universidades do estado de Santa Catarina. Desse modo, será possível averiguar a suficiência de carga horária, comparando-se as ementas e o período do curso em que são ofertadas tais disciplinas, que servem como meios para o aporte de uma escrita proficiente, durante todo o percurso acadêmico.

\section{LETRAMENTO COMO PRÁTICA SOCIAL E SUA INFLUÊNCIA NA ESCRITA ACADÊMICA}

Embora a discussão sobre letramento seja feita há tempos, ainda apresenta relevância no contexto educacional. Soares (2012, p. 18) define o letramento como "o resultado da ação de ensinar ou de aprender a ler e escrever: o estado ou a condição que adquire um grupo social ou um indivíduo como consequência de ter-se apropriado da escrita". Para Ribeiro (2009), o letramento está associado à alfabetização e ao seu uso efetivo, uma vez que pessoas e comunidades são letradas em diferentes espaços e por meio de práticas diversas. Nesse sentido, Rojo (2012) discorre sobre os multiletramentos, conceito construído

\footnotetext{
3 PIT (Produção e Interpretação de Textos): nomenclatura genérica utilizada neste artigo como referência às disciplinas afins que tratam desta temática.
} 
Criar Educação, Criciúma, v. 9, № 3, ago/dez. 2020 - PPGE - UNESC - ISSN 2317-2452

por um grupo de pesquisadores chamado Grupo de Nova Londres - GNL, a partir de um colóquio realizado em Nova Londres, Connecticut (EUA), em 1996. Os multiletramentos constituem-se de dois modos de multiplicidade existentes nas sociedades: "a multiplicidade cultural das populações e a multiplicidade semiótica de constituição dos textos por meio dos quais ela se informa e se comunica" (ROJO, 2012, p. 13). Desta forma, a esfera social contribui substancialmente para o desenvolvimento do letramento e das diferentes formas de escrever.

Para Preto-Bay (2007), a produção escrita revela as estruturas sociais das comunidades a que pertence, o que permite o entendimento das relações entre os sujeitos e a adesão aos valores e princípios dessas comunidades. Portanto, a relação com textos escritos revela a "participação legítima em comunidades culturais, políticas, religiosas e laborais e é, ao mesmo tempo, um ponto de acesso a comunidades a que ainda não pertencemos" (PRETO-BAY, 2007, p. 18). De fato, a escrita se constitui uma importante ferramenta de comunicação e de expressão cultural, logo, de acesso a grupos e bens.

Também a popularização da tecnologia e a expansão das mídias digitais proporcionam mudanças em termos de leitura e escrita. Preto-Bay (2007) salienta a livre circulação de uma gama de dados veiculados na modalidade escrita e aponta que "a produção e o consumo de textos revelam-se progressivamente como catalisador social de participação e acesso a fontes de conhecimento e, consequentemente, de poder" (PRETO-BAY, 2007, p. 18). Considerando esse avanço do cenário tecnológico, é possível reconhecer a inserção e expansão de novas práticas de letramento. "Uma das questões que mais parece inquietar pesquisadores da linguagem e da leitura é em que medida novas práticas de ler e escrever afetam/alteram/influenciam a cognição do novo leitor" (RIBEIRO, 2009, p. 76). Diante de tal contexto, é fundamental perceber que:

Não há limites para o letramento uma vez que a humanidade sempre inventará formas novas de escrever, novos gêneros de texto, suportes de leitura, etc., de acordo com as infinitas necessidades que temos e teremos. A Internet e as máquinas digitais estão entre nossas opções mais recentes.

A relação entre os dispositivos para a comunicação foi recentemente 
Criar Educação, Criciúma, v. 9, nº 3, ago/dez. 2020 - PPGE - UNESC - ISSN 2317-2452 reconfigurada, consequentemente, as possibilidades e as exigências do letramento, também. (RIBEIRO, 2009, p. 77-78).

A citação acima vem alicerçar a influência do universo digital na escrita. Consequentemente, faz-se pertinente abordar os fatores positivos e negativos de tal afirmação, ao passo que, a rapidez com se propagam novos modos de escrever ecoa consistentemente no desenvolvimento da escrita, foco deste estudo.

Indiscutivelmente, o acesso às fontes científicas, obras literárias, clássicos e uma infinidade de textos dos mais variados gêneros disponibilizados na Internet suprem, de certo modo, a necessidade de contato e percepção de diferentes formas de escrever. Em contrapartida, há uma intervenção negativa no que compete à informalidade que acomete a escrita, seja pelo uso indiscriminado de termos específicos da linguagem virtual, seja pela forma coloquial e superficial com que é expressa.

Vitória e Christofoli (2013) advertem sobre a dificuldade em lidar com a escrita sem considerar a heterogeneidade do universo social, suas contradições e diferenças. Soares (2012) considera a escrita um conjunto de habilidades e comportamentos que se desdobram desde um simples bilhete até uma tese de doutorado. Aponta, ainda, que há uma diversidade de tipos, assim como de níveis de letramento, de acordo com as necessidades e demandas dos indivíduos e do meio, prezando o contexto social e cultural.

Entende-se que as sociedades estão em constante transformação, o que demanda uma aculturação em termos de escrita. Nesse sentido, é possível assumir uma forma de escrever diferente daquela adquirida no decorrer da vida, deixando de lado influências e particularidades para se apropriar de uma escrita mais imponente.

Apoiado em seu aspecto sociocultural, o letramento é apontado como uma prática social. Fischer (2007) evidencia que a participação nas práticas de letramento, no que se refere à leitura, escrita e oralidade são formas culturais de uso da linguagem, nas quais estão subentendidas as relações de poder, advindas das experiências e saberes experimentados no decorrer da vida. Evidenciam-se, nesse viés, as relações interpessoais e as relações de mundo, as construções de fala, 
Criar Educação, Criciúma, v. 9, nº 3, ago/dez. 2020 - PPGE - UNESC - ISSN 2317-2452

discurso e sentidos, além do compartilhamento de ideologias e identidades sociais. Incontestavelmente, a influência do meio social e cultural está arraigada no desenvolvimento letrado dos sujeitos, envolvendo "o caráter social, situado e histórico do letramento, o qual é responsável por caracterizar a condição letrada de um sujeito, em um situado espaço da sociedade e em particular momento histórico de sua trajetória pessoal e social” (FISCHER, 2007, p. 26). Percebe-se então, a estreita relação que possui o letramento com o contexto social em que cada sujeito está inserido, pois, as influências do meio social e cultural contribuem significativamente para o desenvolvimento do letramento.

A compreensão de como se dá o ingresso dos acadêmicos em um curso superior, perante uma concepção sociocultural de letramento, tem influência de vários aspectos passíveis de análise. Destacam-se, segundo a ótica de Fischer (2007), o conhecimento de identidades que formam a constituição do letramento dos sujeitos; os objetivos de estarem no curso escolhido; o modo como os professores conduzem as experiências de letramento, observando seus próprios propósitos e também dos acadêmicos; as interações, movimentos e encaminhamentos que ocorrem em sala de aula, que exacerbam a formação do letramento nos ingressantes do cenário acadêmico. "Fica, então, difícil lidar com a escrita sem contemplar este universo social marcado pela heterogeneidade e pelas contradições inerentes a qualquer processo que abriga diferenças." (VITÓRIA; CHRISTOFOLI, 2013, p. 53). Desta forma, reforça-se a premissa de que o letramento está intimamente ligado à diversidade social e cultural dos acadêmicos que ingressam na universidade.

Levando em consideração as particularidades aqui apresentadas, observa-se que se trata de uma faceta complexa, pois compreende muitos aspectos que precisam ser ponderados. Inegavelmente, a prática da escrita configura-se como um comportamento social, a qual legitima o letramento adquirido ao longo da vida e das interações sociais. 
Criar Educação, Criciúma, v. 9, № 3, ago/dez. 2020 - PPGE - UNESC - ISSN 2317-2452

\section{A ESCRITA COMO MECANISMO DO DISCURSO ACADÊMICO}

Constituinte do universo acadêmico, a escrita reflete, dentre outras coisas, a interação dos sujeitos com o saber científico, por meio da linguagem. $O$ ingresso na academia deve proporcionar o refinamento das práticas de escrita que permeiam a produção científica. Miranda e Campos (2014) ressaltam que a universidade é um campo privilegiado para a produção de conhecimento científico, contudo, cabe aos sujeitos ingressantes aprimorar capacidades e competências para sistematizar esse conhecimento. Assim, a universidade "pressupõe que esse sujeito, por meio de sua relação com o conhecimento culturalmente sistematizado, possa dizer algo capaz de transformar e ser transformado, ao ser submetido aos efeitos da linguagem acadêmica." (MIRANDA; CAMPOS, 2014, p. 1207).

No entanto, o panorama demonstrado pelas universidades revela uma lacuna no processo ensino-aprendizagem da escrita de textos, pois, geralmente, os acadêmicos encontram entraves em produzi-los. Indaga-se a respeito do conhecimento prévio dos acadêmicos sobre os gêneros textuais exigidos no ensino superior, pois dificilmente demonstrarão proficiência sobre algo que ainda não aprenderam. Por esse motivo, Vitória e Christofoli (2013) destacam que é fundamental haver um exercício reflexivo no âmbito da escrita, sendo necessário disponibilizar o contato a textos de gêneros variados e promover uma reflexão profícua antes e sempre que seja solicitada uma produção escrita.

Verdadeiramente, o problema se propaga quando a produção escrita enfoca uma temática que demanda conhecimentos específicos e insta o alinhamento entre aspectos teóricos e práticos, o que pode dar indícios de precária familiaridade com textos de tal natureza (VITÓRIA; CHRISTOFOLI, 2013).

Diante de um discurso de crise do letramento universitário nas vozes dos docentes, identificam-se desafios pertinentes relacionados ao contexto individual dos sujeitos. A dificuldade em envolver os acadêmicos em atividades de leitura e escrita, conforme Fischer (2007), ocorre em virtude dos conhecimentos insuficientes sobre o assunto e sobre os gêneros discursivos requeridos para leitura, além da falta de 
Criar Educação, Criciúma, v. 9, № 3, ago/dez. 2020 - PPGE - UNESC - ISSN 2317-2452 tempo para os estudos, considerando que a maioria está inserida no mercado de trabalho. É válido dizer que uma parcela significativa não consegue superar as dificuldades no decorrer do curso.

Não raro, a elaboração do Trabalho de Conclusão de Curso (TCC) tornase um dos maiores pesadelos dos concluintes. Motivo de estresse e sentimento de impotência, a dificuldade em assimilar, analisar e construir textos se faz presente no cotidiano acadêmico. Aqueles que adentram o universo acadêmico trazem muita bagagem e conhecimento de mundo, todavia, têm dificuldade em traspor tais conhecimentos para a modalidade escrita. Por isso, é

[...] importante incentivar a discussão, a socialização das limitações e das dificuldades apresentadas pelos alunos, no diz respeito à escrita, já que esta representa importante habilidade para que 0 aluno efetivamente usufrua de maneira plena das práticas sociais da língua. (VITÓRIA; CHRISTOFOLI, 2013, p. 42).

Perante essa afirmação, entende-se que a escrita se constitui como condição essencial para o ensino superior, objetivando a "inserção e interação dos alunos com/no meio acadêmico, familiarizando-os com linguagens específicas das áreas de conhecimento, preparando-os para atender a demanda que todo curso superior emana." (VITÓRIA; CHRISTOFOLI, 2013, p. 43). Desta forma, a inclusão dos sujeitos, por meio da escrita, é de grande importância para o desenvolvimento também social dos acadêmicos, no ambiente universitário.

Em suma, priorizar discussões e reflexões sobre a escrita acadêmica torna-se fator fundamental para se projetar ações que levem à evolução da educação superior num todo.

\section{A DISCIPLINA DE PRODUÇÃO E INTERPRETAÇÃO DE TEXTOS (PIT) COMO APORTE PARA O DESENVOLVIMENTO DA ESCRITA NO ENSINO SUPERIOR}

A incumbência de escrever requer, além de técnica e entendimento sobre determinado gênero discursivo, o conhecimento da língua como instrumento que legitima o texto produzido. Em se tratando de conhecimento da língua, Geraldi 
Criar Educação, Criciúma, v. 9, № 3, ago/dez. 2020 - PPGE - UNESC - ISSN 2317-2452

(2006) aponta para o seu baixo nível de uso, seja na modalidade oral ou escrita. Isso retrata certa defasagem no processo de ensino da língua portuguesa. Dada a sua importância, Possenti (2006, p. 36) conceitua o domínio da língua como "o resultado de práticas efetivas, significativas, contextualizadas". Para Figueiredo e Bonini (2006), o domínio da língua condiciona o texto acadêmico a sua aceitabilidade e credibilidade, mas não apenas isso, fatores como a elaboração de uma linha argumentativa e o conhecimento específico sobre o tema são indispensáveis para que esse conjunto de habilidades funcione efetivamente. "Muitos trabalhos [...] apresentam-se como uma 'colcha de retalhos' composta de noções diversas (e muitas vezes desconectadas) sobre um campo" (FIGUEIREDO; BONINI, 2006, p. 414). Tal afirmação define com propriedade como se apresentam, de modo geral, os textos acadêmicos, não apenas no início, mas em todo o percurso da graduação.

Vitória e Christofoli (2013) destacam a relevância em se criar condições para que os sujeitos sejam capazes de desenvolver a escrita das mais diversas formas, propondo estratégias de ensino que forneçam um acesso significativo às práticas sociais da língua escrita. Figueiredo e Bonini (2006, p. 428) endossam as afirmações aqui dispostas ao ressaltar que "aprender a escrever implica aprender não só a compor e construir um texto em termos lingüísticos (sic), mas entender por quem, onde, quando, em que condições, com que recursos, e para que fins o texto é escrito".

Por esse motivo, o trabalho com a escrita deve estar inserido nas práticas docentes, a fim de proporcionar aos acadêmicos elementos para permear o universo dos diferentes gêneros solicitados na graduação. "Daí a importância de agregarmos nas nossas práticas docentes, além da oralidade, um trabalho voltado para os componentes básicos da expressão escrita, que são o código escrito, propriamente dito, e a composição da escrita." (VITÓRIA; CHRISTÓFOLI, 2013. p. 46).

Neste caso, as ementas das disciplinas devem considerar tais particularidades e necessidades da escrita acadêmica, sendo capazes de propiciar um aporte para o seu desenvolvimento. Não obstante, os ingressantes do ensino superior desconhecem ou não apresentam afinidade com os gêneros acadêmicos, 0 
Criar Educação, Criciúma, v. 9, № 3, ago/dez. 2020 - PPGE - UNESC - ISSN 2317-2452

que confere a hegemonia de um único gênero: o "trabalho". Marinho (2010) discorre sobre o trabalho, como um gênero genérico e cristalizado nas salas de aula e, a necessidade de desconstruí-lo. Isso é necessário pelo fato de que as práticas de escrita dos acadêmicos tornam-se muito semelhantes, resultando em um padrão engessado de texto escolar.

Como já abordado nesse artigo, também Marinho (2010) relata o estranhamento, por parte dos professores de graduação, ao se depararem com ingressantes pouco familiarizados com as práticas de leitura e produção dos gêneros que sustentam as singularidades do contexto acadêmico. Sobretudo, por acreditarem que "o aluno aprovado no vestibular teria sido avaliado nas suas habilidades de leitura e de escrita e, consequentemente, estaria apto a ler e a escrever com propriedade" (MARINHO, 2010, p. 366). Embora o Exame Nacional do Ensino Médio - ENEM seja uma das maiores portas para o ingresso no ensino superior, há de se ressaltar as novas formas de acesso por mérito escolar, que constituem uma fatia significativa nas vagas das universidades, não sendo neste caso, o candidato avaliado em suas competências de apropriação da escrita.

A reflexão que se faz, nesse sentido é a de que, deveriam esses estudantes ter aprendido no ensino médio gêneros que são próprios da esfera acadêmica? Na visão de Marinho (2010) a universidade é lugar onde o aprendizado e a produção desses gêneros se vincula:

Os gêneros acadêmicos não constituem conteúdo e nem práticas preferenciais nas escolas de ensino fundamental médio. A leitura e a escrita desses gêneros de referência na academia [...] são realizadas, de preferência, na universidade, porque é nessa instituição que são produzidos, por necessidades próprias, esses gêneros (MARINHO, 2010, p. 366).

Diante do exposto, percebe-se claramente a urgência de amparo em relação ao ensino e aprendizagem da escrita nos cursos de graduação. Por esses e outros motivos é que a disciplina de PIT pode alavancar o processo de aprendizagem, resultando na construção de textos acadêmicos de maior qualidade. Lamentavelmente, essa disciplina é disponibilizada na modalidade optativa por 
Criar Educação, Criciúma, v. 9, № 3, ago/dez. 2020 - PPGE - UNESC - ISSN 2317-2452 muitas instituições de ensino. Por outras, nem mesmo chega a ser oferecida, podendo comprometer a evolução da escrita acadêmica ao longo do curso. "Oportunizar a ampliação do desempenho linguístico do aluno, possibilitando-lhe o domínio de novos recursos expressivos deveria ser uma preocupação constante no Ensino Superior" (VITÓRIA; CHRISTOFOLI, 2013, p. 48). Compreende-se, deste modo, que as universidades precisam ampliar o olhar para a produção escrita, oferecendo possibilidades para o ensino e aprendizagem da mesma, no decorrer dos cursos de graduação, a fim de corrigir possíveis problemas e, também, aprimorá-la.

É visível a importância da disciplina de PIT no cenário acadêmico, pois compete ao Ensino Superior oferecer alternativas e experiências que auxiliem os graduandos a superar as barreiras de produções escritas rasas, como estratégia compensatória, para as defasagens expostas. Vitória e Christofoli (2013, p. 50) validam essa proposição, ao destacar que "é função do Ensino Superior oferecer possibilidades de ampliação do repertório do aluno, para que a escrita exigida na universidade se veja afetada e favorecida por tal repertório". Novamente, se reforça o argumento de que a universidade precisa oferecer as condições necessárias para que os acadêmicos possam desenvolver uma escrita de qualidade, o que reflete na qualidade do ensino como um todo, elevando assim, o potencial das produções textuais.

Nesse sentido, a disciplina de PIT pode assumir um papel fundamental para o aperfeiçoamento da leitura e escrita, preparando de modo contundente os acadêmicos para as diversas situações em que os textos acadêmicos serão utilizados.

\section{A OFERTA DA DISCIPLINA DE PIT EM UNIVERSIDADES DE SANTA CATARINA}

Buscando averiguar a existência de uma disciplina que aborde especificamente as questões de escrita, leitura e interpretação, realizou-se um levantamento nos websites de algumas universidades do estado de Santa Catarina. 
Criar Educação, Criciúma, v. 9, ํo 3, ago/dez. 2020 - PPGE - UNESC - ISSN 2317-2452

A metodologia apresenta-se como um estudo de natureza básica, que segundo Boaventura (2004, p. 56) "é a investigação que procura aumentar o conhecimento sobre o homem, a natureza e a própria humanidade." De abordagem qualitativa, caracterizada como "fonte direta de dados no ambiente natural, [...] é uma pesquisa descritiva, em que os investigadores, interessando-se mais pelo processo do que pelos resultados, examinam os dados de maneira indutiva e privilegiam o significado" (BOGDAN; BIKLEN, 1994 apud BOAVENTURA, 2004, p. $56)$.

Quanto ao procedimento, optou-se pelo bibliográfico, o qual se utiliza de referências teóricas que buscam elucidar um problema (CERVO; BERVIAN; SILVA, 2007). Também foi utilizado o procedimento documental. A pesquisa da bibliografia foi realizada por meio de buscas de artigos, em plataformas e bancos de dados científicos, além de obras bibliográficas. Foram selecionados os que apresentaram abordagens relevantes ao tema desse estudo, colaborando para o esclarecimento das indagações propostas. O procedimento documental realizou-se por meio de análises nos currículos e Projetos Pedagógicos de Cursos (PPCs) de cursos de graduação, disponibilizados nos websites das universidades.

Optou-se pela escolha de oito Instituições de Ensino Superior (IES) não públicas do estado de Santa Catarina para a coleta de dados. Foram elencados quatro cursos comuns a todas as IES. Os cursos de Administração e Direito foram selecionados em função da alta demanda e por serem cursos consolidados, dado o tempo de existência no mercado. O curso de Engenharia Civil foi elencado pela tradição, boa aceitação e, também, por sua consolidação no mercado. Por fim, Pedagogia, sendo este o curso que demanda o maior número de acadêmicos do país, dada a sua relevância na esfera educacional.

O quadro a seguir demonstra a oferta da disciplina de PIT ou similares, bem como a carga horária, modalidade, ementas e períodos do curso em que são disponibilizadas as disciplinas.

Quadro 1 - Oferta da disciplina de PIT ou similares. 
Criar Educação, Criciúma, v. 9, ㄲo 3, ago/dez. 2020 - PPGE - UNESC - ISSN 2317-2452

\begin{tabular}{|c|c|c|c|c|c|c|}
\hline Universidade & Curso & $\begin{array}{l}\text { Disciplina PIT } \\
\text { ou similar }\end{array}$ & $\begin{array}{l}\text { Modalida- } \\
\text { de }\end{array}$ & $\begin{array}{c}\text { Semes- } \\
\text { tre }\end{array}$ & Créditos & Ementa \\
\hline \multirow[b]{2}{*}{ FURB } & \multirow{2}{*}{ 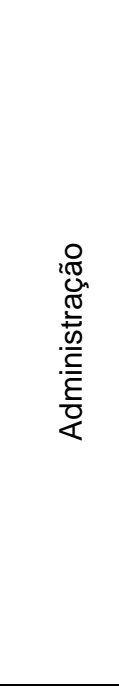 } & $\begin{array}{l}\text { Comunicação } \\
\text { Empresarial } \\
\text { Escrita e Oral }\end{array}$ & Obrigatória & $1^{\circ}$ & 04 & $\begin{array}{l}\text { Habilidades necessárias e } \\
\text { recursos aplicados; a norma } \\
\text { culta como fator importante } \\
\text { para a comunicação escrita } \\
\text { e oral. A leitura e a } \\
\text { produção escrita. A análise } \\
\text { de problemas de redação e } \\
\text { redação comercial. Ténicas } \\
\text { de oratória. }\end{array}$ \\
\hline & & $\begin{array}{l}\text { Linguagem } \\
\text { Científica }\end{array}$ & Optativa & $2^{0}$ & 04 & 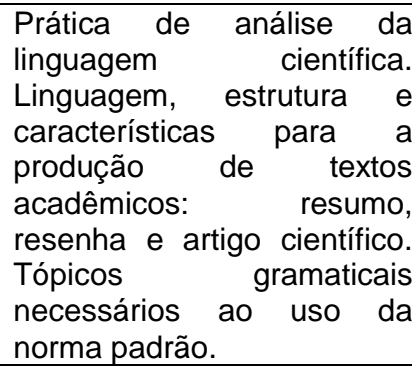 \\
\hline \multirow{3}{*}{ FURB } & \multirow{3}{*}{ 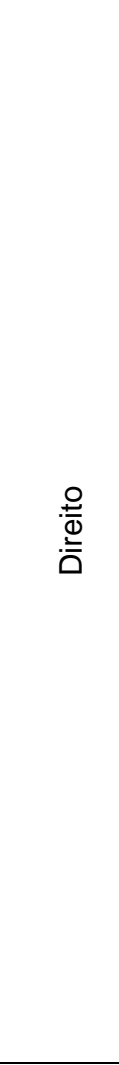 } & $\begin{array}{l}\text { Linguagem e } \\
\text { Argumentação } \\
\text { Jurídica }\end{array}$ & Obrigatória & $2^{0}$ & 02 & $\begin{array}{l}\text { Linguagem e e semiologia. } \\
\text { Usos da linguagem. } \\
\text { Principais correntes da } \\
\text { semiologia. Formas de de } \\
\text { argumentação. Falácias não } \\
\text { formais e argumentos. } \\
\text { Técnicas de argumentação } \\
\text { nas práticas jurídicas. } \\
\text { Senso comum teórico dos } \\
\text { juristas: verdade e ideologia. } \\
\text { Lógica Jurídica e nova } \\
\text { retórica. Teorias relativas ao } \\
\text { raciocínio judiciário. }\end{array}$ \\
\hline & & $\begin{array}{l}\text { Oficina de } \\
\text { Produção } \\
\text { Textual e } \\
\text { Oratória }\end{array}$ & Obrigatória & $3^{0}$ & 02 & $\begin{array}{l}\text { Texto narrativo, descritivo e } \\
\text { dissertativo. Interpretação e } \\
\text { produção textual. Semântica } \\
\text { Jurídica. Linguagem e } \\
\text { oratória. }\end{array}$ \\
\hline & & $\begin{array}{l}\text { Linguagem } \\
\text { Científica }\end{array}$ & Optativa & $2^{0}$ & 04 & 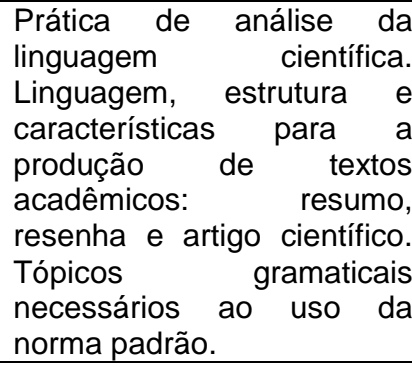 \\
\hline
\end{tabular}




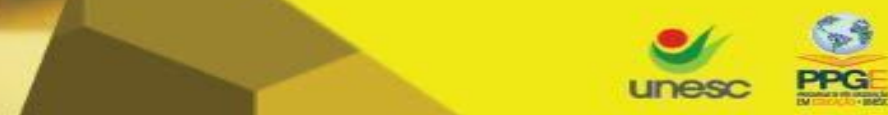
Unahee
Unidsede. Acodamice
do Hulmaniododot,
dianciat ediunesc

Criar Educação, Criciúma, v. 9, oㅜ 3, ago/dez. 2020 - PPGE - UNESC - ISSN 2317-2452

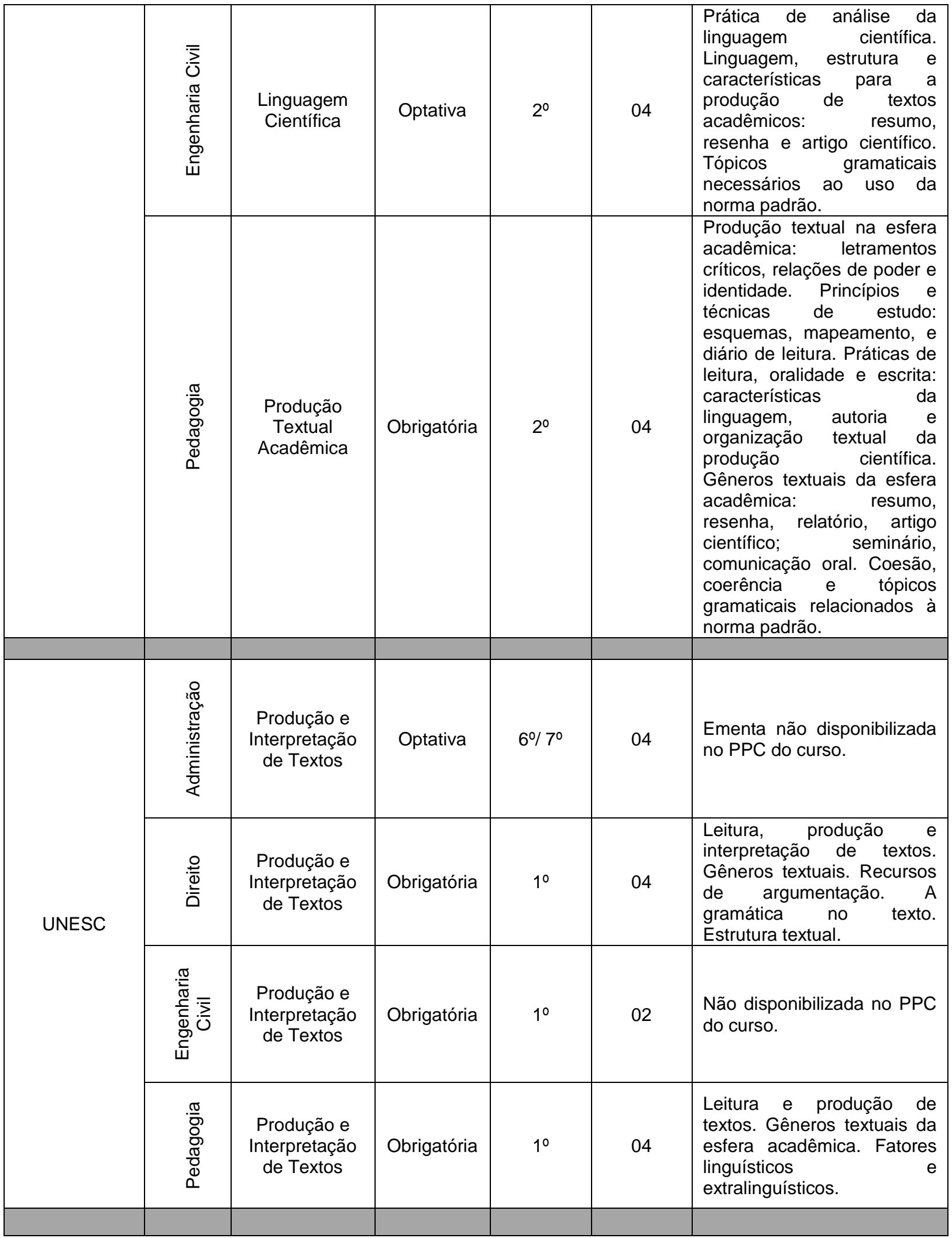


Criar Educação, Criciúma, v. 9, ㄲo 3, ago/dez. 2020 - PPGE - UNESC - ISSN 2317-2452

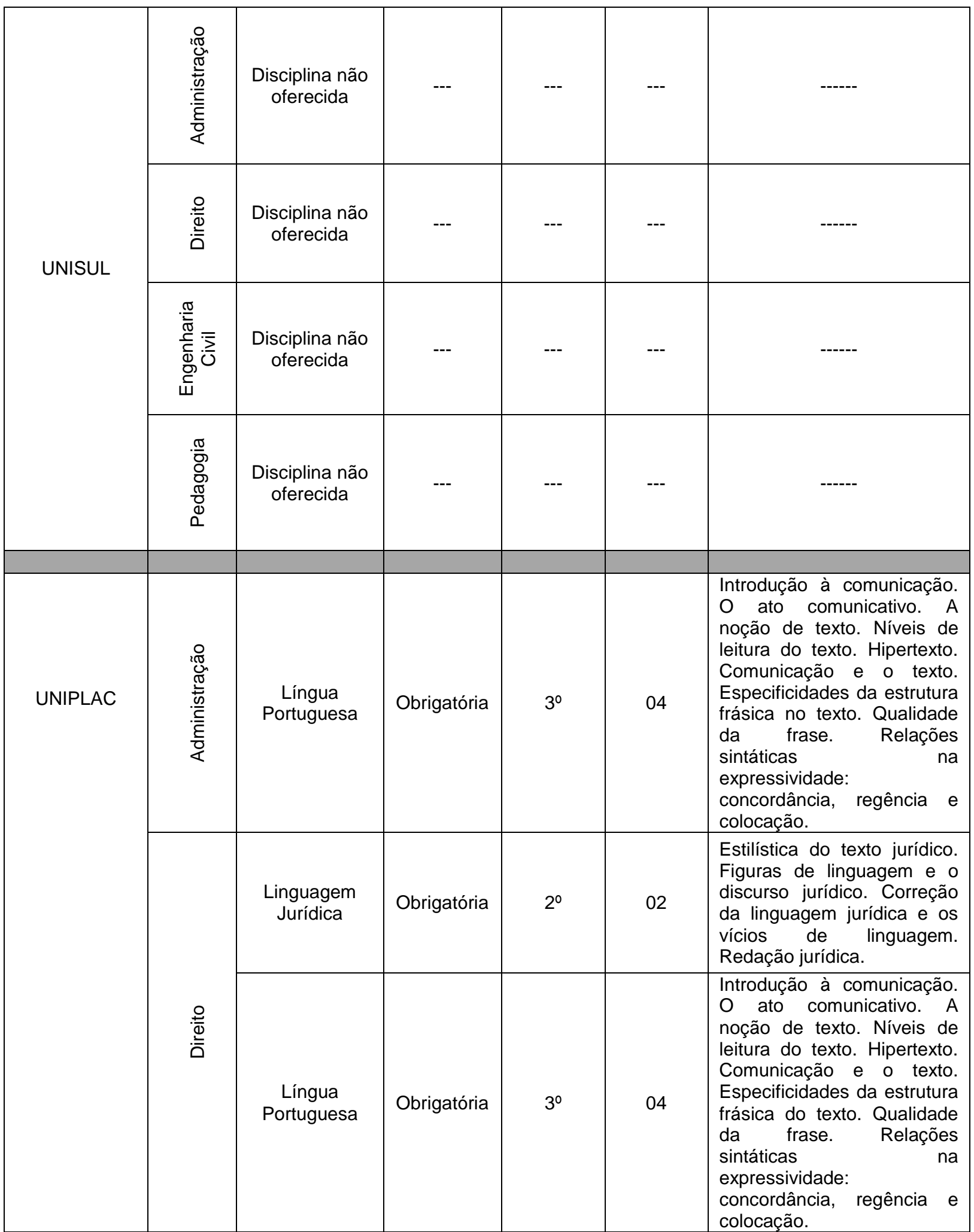



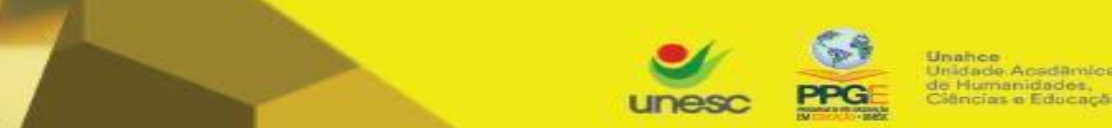

Criar Educação, Criciúma, v. 9, oㅜ 3, ago/dez. 2020 - PPGE - UNESC - ISSN 2317-2452

\begin{tabular}{|c|c|c|c|c|c|c|}
\hline \multirow[t]{2}{*}{ UNIPLAC } & 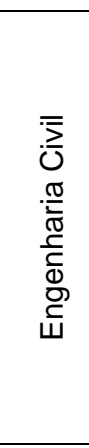 & $\begin{array}{l}\text { Língua } \\
\text { Portuguesa }\end{array}$ & Obrigatória & $3^{0}$ & 04 & $\begin{array}{l}\text { Introdução à comunicação. } \\
\text { O ato comunicativo. A } \\
\text { noção de texto. Níveis de } \\
\text { leitura do texto. Hipertexto. } \\
\text { Comunicação e o texto. } \\
\text { Especificidades da estrutura } \\
\text { frásica do texto. Qualidade } \\
\text { da frase. Relações } \\
\text { sintáticas } \\
\text { expressividade: } \\
\text { concordância, regência e } \\
\text { colocaçãa. }\end{array}$ \\
\hline & $\begin{array}{l}\frac{\pi}{7} \\
0 \\
0 \\
\frac{\pi}{0} \\
0 \\
0\end{array}$ & $\begin{array}{l}\text { Língua } \\
\text { Portuguesa }\end{array}$ & Obrigatória & $3^{0}$ & 04 & $\begin{array}{l}\text { Introdução à comunicação. } \\
\text { O ato comunicativo. A } \\
\text { noção de texto. Níveis de } \\
\text { leitura do texto. Hipertexto. } \\
\text { Comunicação e o texto. } \\
\text { Especificidades da estrutura } \\
\text { frásica do texto. Qualidade } \\
\text { da frase. Relações } \\
\text { sintáticas } \\
\text { expressividade: } \\
\text { concordância, regência e } \\
\text { colocação. }\end{array}$ \\
\hline \multirow{4}{*}{ UNIVALI } & 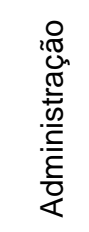 & $\begin{array}{l}\text { Disciplina não } \\
\text { oferecida }\end{array}$ & --- & --- & --- & ----- \\
\hline & 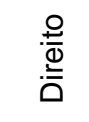 & $\begin{array}{l}\text { Linguagem } \\
\text { Jurídica }\end{array}$ & Obrigatória & $2^{0}$ & 04 & $\begin{array}{l}\text { Não disponibilizada no PPC } \\
\text { do curso. }\end{array}$ \\
\hline & 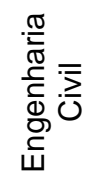 & $\begin{array}{l}\text { Disciplina não } \\
\text { oferecida }\end{array}$ & --- & --- & --- & ----- \\
\hline & $\begin{array}{l}\frac{\pi}{8} \\
0 \\
\frac{\pi}{0} \\
\frac{0}{0} \\
0\end{array}$ & $\begin{array}{l}\text { Leitura, } \\
\text { Interpretação } \\
\text { e Produção } \\
\text { Textual }\end{array}$ & Obrigatória & $1^{0}$ & 04 & $\begin{array}{l}\text { Não disponibilizada no PPC } \\
\text { do curso. }\end{array}$ \\
\hline UNIVILLE & 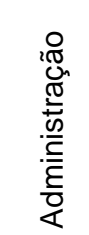 & $\begin{array}{l}\text { Disciplina não } \\
\text { oferecida }\end{array}$ & --- & --- & --- & ----- \\
\hline
\end{tabular}



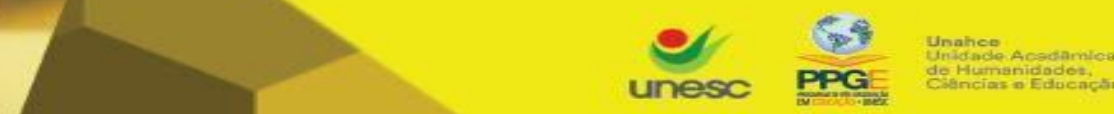

Criar Educação, Criciúma, v. 9, oㅜ 3, ago/dez. 2020 - PPGE - UNESC - ISSN 2317-2452

\begin{tabular}{|c|c|c|c|c|c|c|}
\hline & \multirow{2}{*}{ 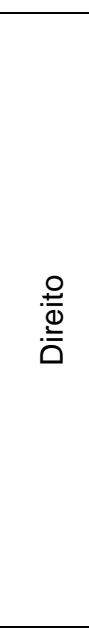 } & $\begin{array}{c}\text { Linguagem } \\
\text { Jurídica I }\end{array}$ & Obrigatória & $2^{\circ}$ & 02 & $\begin{array}{l}\text { A palavra como instrumento } \\
\text { de comunicação oral e } \\
\text { escrita. Como ler, entender } \\
\text { e redigir um texto. Leitura } \\
\text { em público. A redação } \\
\text { forense. } \\
\text { jurídico. Vocabulário } \\
\text { jurídica. Argumentação }\end{array}$ \\
\hline & & $\begin{array}{l}\text { Linguagem } \\
\text { Jurídica II }\end{array}$ & Obrigatória & $3^{\circ}$ & 04 & 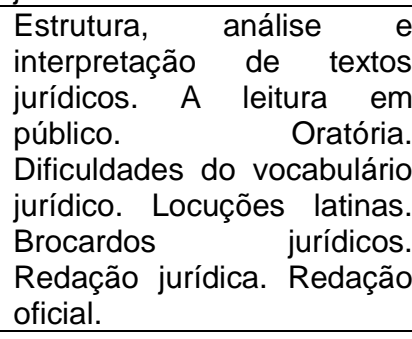 \\
\hline & 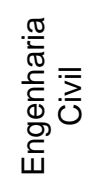 & $\begin{array}{c}\text { Disciplina não } \\
\text { oferecida }\end{array}$ & --- & --- & --- & ------ \\
\hline & $\begin{array}{l}\frac{\pi}{7} \\
\frac{0}{8} \\
\frac{\pi}{0} \\
0 \\
0\end{array}$ & $\begin{array}{l}\text { Práticas de } \\
\text { Leitura e } \\
\text { Escrita }\end{array}$ & Obrigatória & $1^{0}$ & 04 & $\begin{array}{l}\text { Leitura de estudo: o que é, } \\
\text { como se faz, estratégias de } \\
\text { abordagem dos textos. } \\
\text { Práticas de leitura e e } \\
\text { produção de textos (orais e } \\
\text { escritos) da esfera } \\
\text { acadêmica: resenha, } \\
\text { resumo, fichamento, } \\
\text { memorial, crítica, artigo } \\
\text { científico, diário de leitura, } \\
\text { comentários, seminários, } \\
\text { debates, ensaio. }\end{array}$ \\
\hline & 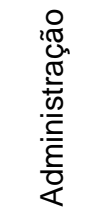 & $\begin{array}{c}\text { Disciplina não } \\
\text { oferecida }\end{array}$ & --- & --- & --- & ----- \\
\hline UNOCHAPECÓ & 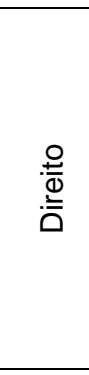 & $\begin{array}{l}\text { Língua } \\
\text { Portuguesa }\end{array}$ & Obrigatória & $1^{\circ}$ & 04 & $\begin{array}{l}\text { Comunicação } \\
\text { Vocabulário jurídico. A A } \\
\text { estrutura frásica na } \\
\text { linguagem jurídica. Revisão } \\
\text { gramatical. } \text { Descrição, } \\
\text { narração, dissertação no } \\
\text { texto jurídico. Análise } \\
\text { linguístico-formal de normas } \\
\text { jurídicas. Produção de } \\
\text { textos }\end{array}$ \\
\hline
\end{tabular}




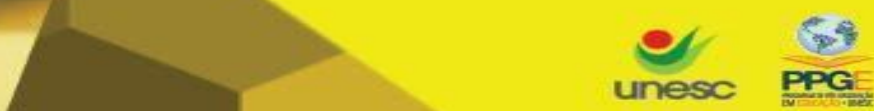
Unahee
Unidsade Acodamica
de Hudmanidodot, diunese

Criar Educação, Criciúma, v. 9, oㅜ 3, ago/dez. 2020 - PPGE - UNESC - ISSN 2317-2452

\begin{tabular}{|c|c|c|c|c|c|c|}
\hline \multirow[b]{2}{*}{ UNOCHAPECÓ } & 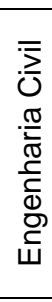 & $\begin{array}{l}\text { Leitura e } \\
\text { Produção de } \\
\text { Textos }\end{array}$ & Obrigatória & $1^{0}$ & 02 & $\begin{array}{l}\text { Produção de textos (orais e } \\
\text { escritos), leitura e análise } \\
\text { linguística de textos em } \\
\text { diferentes gêneros. Coesão } \\
\text { e coerência textual. } \\
\text { Aspectos morfológicos, } \\
\text { sintáticos, semânticos e } \\
\text { pragmáticos. }\end{array}$ \\
\hline & $\begin{array}{l}\frac{\pi}{8} \\
\frac{8}{8} \\
\frac{\pi}{8} \\
0\end{array}$ & $\begin{array}{l}\text { Leitura e } \\
\text { Produção de } \\
\text { Textos }\end{array}$ & Obrigatória & $1^{0}=$ & 02 & $\begin{array}{l}\text { Produção de textos (orais e } \\
\text { escritos), leitura e análise } \\
\text { linguística de textos em } \\
\text { diferentes gêneros. Coesão } \\
\text { e coerência textual. } \\
\text { Aspectos morfológicos, } \\
\text { sintáticos, semânticos e } \\
\text { pragmáticos. }\end{array}$ \\
\hline \multirow[b]{2}{*}{ UNOESC } & 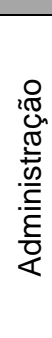 & $\begin{array}{l}\text { Linguagem e } \\
\text { Método } \\
\text { Científico }\end{array}$ & Obrigatória & $1^{0}$ & 04 & $\begin{array}{l}\text { Textos acadêmicos: } \\
\text { tipologia e estrutura. Análise } \\
\text { e interpretação de textos } \\
\text { acadêmicos. Produção de } \\
\text { textos acadêmicos: } \\
\text { estrutura, adequação de } \\
\text { linguagem, norma culta. } \\
\text { Normas da ABNT. Métodos } \\
\text { de estudos na universidade. }\end{array}$ \\
\hline & 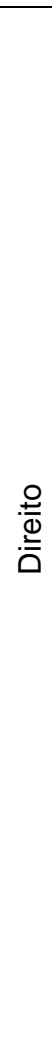 & $\begin{array}{l}\text { Produção de } \\
\text { Texto }\end{array}$ & Obrigatória & 10 & 04 & 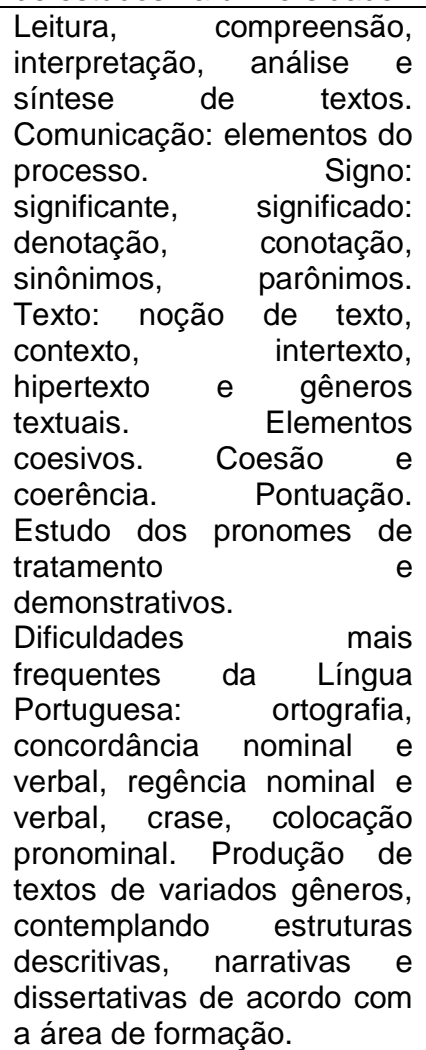 \\
\hline
\end{tabular}


Criar Educação, Criciúma, v. 9, oㅜ 3, ago/dez. 2020 - PPGE - UNESC - ISSN 2317-2452

\begin{tabular}{|c|c|c|c|c|c|c|}
\hline & & $\begin{array}{l}\text { Argumenta- } \\
\text { ção Jurídica }\end{array}$ & Obrigatória & $6^{\circ}$ & 02 & $\begin{array}{l}\text { Estudo da Teoria e Prática } \\
\text { da Argumentação Jurídica. } \\
\text { Desenvolvimento para de } \\
\text { competências para a } \\
\text { produção escrita e oral de } \\
\text { textos jurídicos através da } \\
\text { reflexão crítica sobre a arte } \\
\text { retórica. Análise e uso das } \\
\text { estratégias de apresentação } \\
\text { oral em público. }\end{array}$ \\
\hline \multirow{2}{*}{ UNOESC } & 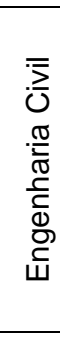 & $\begin{array}{l}\text { Linguagem e } \\
\text { Método } \\
\text { Científico }\end{array}$ & Obrigatória & $1^{0}$ & 04 & $\begin{array}{l}\text { Textos acadêmicos: } \\
\text { tipologia e estrutura. Análise } \\
\text { e interpretação de textos } \\
\text { acadêmicos. Produção de } \\
\text { textos acadêmicos: } \\
\text { estrutura, adequação de } \\
\text { linguagem, norma culta. } \\
\text { Normas da ABNT. Métodos } \\
\text { de estudos na universidade. }\end{array}$ \\
\hline & $\begin{array}{l}\frac{\pi}{0} \\
\frac{\pi}{8} \\
\frac{\pi}{0} \\
0\end{array}$ & $\begin{array}{l}\text { Linguagem e } \\
\text { Método } \\
\text { Científico }\end{array}$ & Obrigatória & 10 & 04 & $\begin{array}{l}\text { Textos acadêmicos: } \\
\text { tipologia e estrutura. Análise } \\
\text { e interpretação de textos } \\
\text { acadêmicos. Produção de } \\
\text { textos acadêmicos: } \\
\text { estrutura, adequação de } \\
\text { linguagem, norma culta. } \\
\text { Normas da ABNT. Métodos } \\
\text { de estudos na universidade. }\end{array}$ \\
\hline
\end{tabular}

Fonte: Quadro elaborado pelos autores a partir de dados fornecidos nos websites dos cursos (2019).

Por meio desse levantamento, observa-se que a oferta da disciplina de PIT, ou outras relacionadas às práticas de leitura e escrita, aparece de forma tímida na maioria das universidades, enquanto que em outras nem fazem parte do currículo. Além disso, são oferecidas exclusivamente no início do curso, por vezes com carga horária reduzida ou na modalidade optativa.

Vale ressaltar que não se refuta, nesse estudo, a possibilidade de as universidades citadas trabalharem, por exemplo, com a abordagem WAC - Writing Across the Curriculum ${ }^{4}$, (inserida atualmente no movimento das metodologias ativas), uma vez que ela possibilita o desenvolvimento da habilidade de escrita bem como de todo o processo comunicativo. Também não se descarta a utilização de outras metodologias interdisciplinares que se dedicam a esse fim, correlacionadas Sobre a abordagem $\underset{\text { a }}{4}$ WAC
https://wac.colostate.edu/resources/wac/intro 
Criar Educação, Criciúma, v. 9, ㄲo 3, ago/dez. 2020 - PPGE - UNESC - ISSN 2317-2452

às disciplinas específicas. De todo modo, não há menção nos documentos analisados sobre a utilização de tais metodologias.

O estudo bibliográfico demonstrou que os ingressantes de cursos superiores enfrentam sérios problemas em termos de letramento acadêmico. Envolvendo habilidades e competências nos campos da leitura, escrita e interpretação de textos, o contexto atual está muito aquém do esperado. Há um despreparo das universidades em atender uma demanda que apresenta, em grande parte, um déficit de aprendizagem desde a Educação Básica.

Muitos autores discorrem sobre a constituição letrada dos acadêmicos e 0 estigma de incompetência, seja na assimilação de conteúdos teóricos, seja na proficiência em produção escrita. Consideradas estas atividades essenciais para o desenvolvimento de outras, torna-se relevante que as universidades propiciem possibilidades para o desenvolvimento das habilidades de escrita, leitura e interpretação de textos. Dentre os meios viáveis, podem se destacar a oferta de disciplinas específicas para esse objetivo em moldes que possam, de fato, suprir ou amenizar a dificuldade encontrada pelos discentes ou, ainda, por meio de metodologias que trabalhem interdisciplinarmente, durante todo o percurso da graduação.

\section{CONCLUSÃO}

Percebendo-se a importância de solucionar essa fragilidade encontrada nos cursos de graduação, é relevante repensar a atuação e a contribuição da disciplina de PIT, ou similares, nos cursos de graduação. Faz-se importante também, avaliar a carga horária, ementas, modalidades, períodos do curso em que são ofertadas tais disciplinas e, ainda, os métodos de ensino-aprendizagem empregados.

A realidade aqui apresentada destoa do cenário esperado no Ensino Superior, em termos de oferta e frequência de disciplinas ou metodologias que atuem substancialmente no aperfeiçoamento das habilidades de leitura e escrita. 
Criar Educação, Criciúma, v. 9, nº 3, ago/dez. 2020 - PPGE - UNESC - ISSN 2317-2452

Nosso estudo refuta a ideia de que os ingressantes do ensino superior adentram a universidade com competências de letramento suficientes para uma boa performance.

Sendo a escrita acadêmica fundamentalmente necessária durante todo o percurso acadêmico, torna-se prejudicada pela defasagem e dificuldade que os ingressantes demonstram, já nas primeiras fases dos cursos. Percebem-se, além do déficit de letramento, outros desafios relacionados ao processo de ensinoaprendizagem, como problemas relacionados à linguagem acadêmica, que se constitui em um universo sociocultural e precisa ser adaptado à área científica.

Ressalta-se ainda, segundo os autores, que tais práticas precisam ser ensinadas, sendo a universidade um campo privilegiado e o cenário onde se desenvolvem, de fato, os gêneros acadêmicos. Por isso é essencial que sejam repensados os processos de ensino-aprendizagem que a universidade utiliza para sanar tais dificuldades e a disponibilização de disciplinas que enfoquem a apropriação da escrita acadêmica. Ainda assim, torna-se possível e significativo trabalhar a escrita acadêmica nas disciplinas específicas, a exemplo do WAC ou outras metodologias ativas interdisciplinares.

Portanto, seriam pertinentes futuros estudos sobre o papel da disciplina de Produção e Interpretação de Textos e também metodologias interdisciplinares nos cursos de graduação, conhecendo seus objetivos e averiguando se a sistemática empregada está sendo capaz de atender aos anseios de um cenário que "patina" no avanço de uma escrita condizente e necessária à educação superior.

\section{REFERÊNCIAS}

BOAVENTURA, Edivaldo M. Metodologia da Pesquisa: monografia, dissertação, tese. $1^{a}$ ed. São Paulo: Atlas, 2007.

CERVO, Amado Luiz; BERVIAN, Pedro Alcino; SILVA, Roberto da. Metodologia Científica. 6. ed. São Paulo: Pearson, 2007. 
Criar Educação, Criciúma, v. 9, ํㅡ 3, ago/dez. 2020 - PPGE - UNESC - ISSN 2317-2452

FIGUEIREDO, Débora de Carvalho; BONINI, Adair. Práticas discursivas e ensino do texto acadêmico: concepções de alunos de mestrado sobre a escrita. Linguagem em (Dis)curso, v.6, n.3, p. 413-446, out. 2010. Disponível em: http://portaldeperiodicos.unisul.br/index.php/Linguagem_Discurso/article/view/344 . Acesso em: 28 jan. 2019.

FISCHER, Adriana. A construção de letramentos na esfera acadêmica. 2007. 341 f. Tese (Doutorado em Linguística) - Centro de Comunicação e Expressão, Universidade Federal de Santa Catarina, Florianópolis, 2007. Disponível em: http://repositorio.ufsc.br/xmlui/handle/123456789/89764. Acesso em 15 nov. 2018.

FURB. Universidade Regional de Blumenau. Matriz Curricular do Curso de Engenharia Civil. Blumenau, 2018. Disponível em: http://www.furb.br/web/upl/graduacao/matriz/201906181709160.Engenharia\%20Civil \%20-\%202015\%20Mat-Vesp.pdf. Acesso em: 22 jul. 2019.

FURB. Universidade Regional de Blumenau. Matriz Curricular do Curso de Pedagogia. Blumenau, 2017. Disponível em: http://www.furb.br/web/upl/graduacao/matriz/201802281104160.Registro\%20193\%2 OPedagogia.pdf. Acesso em 22 jul. 2019.

FURB. Universidade Regional de Blumenau. Projeto Pedagógico do Curso de Administração. Blumenau, 2011. Disponível em: http://www.furb.br/web/upl/graduacao/projeto_pedagogico/201807251638140.PPC\% 20ADMINISTRACAO\%202011.pdf. Acesso em: 25 maio 2019.

FURB. Universidade Regional de Blumenau. Projeto Pedagógico do Curso de Direito. Blumenau, 2013. Disponível em:

http://www.furb.br/web/upl/graduacao/projeto_pedagogico/201711071526440.PPCCurso_de_Direito.pdf. Acesso em: 25 maio 2019.

GERALDI, João Wanderley. Concepções de linguagem e ensino de português. In: GERALDI, João Wanderley (Org.); ALMEIDA, Milton José de et. al. O texto na sala de aula. 4. ed. São Paulo: Ática, 2006.

MARINHO, Marildes. A escrita nas práticas de letramento acadêmico. Revista Brasileira de Linguística Aplicada, Minas Gerais, v. 10, n. 2, p. 363-386, abr./jun. 2010. Disponível em: http://www.redalyc.org/articulo.oa?id=339829613005. Acesso em: 28 jan. 2019.

MIRANDA, Maria Aparecida da Silva; CAMPOS, Sulemi Fabiano. Escrita acadêmica: o pesquisador e sua relação com a teoria. Estudos Linguísticos, São Paulo, v. 43, n. 3, p. 1207-1220, set./dez. 2014. Disponível em: https://revistas.gel.org.br/estudoslinguisticos/article/viewFile/517/393. Acesso em: 14 dez. 2018. 
Criar Educação, Criciúma, v. 9, nº 3, ago/dez. 2020 - PPGE - UNESC - ISSN 2317-2452

POSSENTI, Sírio. Sobre o ensino de português na escola. In: GERALDI, João Wanderley (Org.); ALMEIDA, Milton José de et. al. O texto na sala de aula. 4. ed. São Paulo: Ática, 2006.

PRETO-BAY, Ana Maria Raposo. Acesso social, práticas educativas e mudanças teórico-pedagógicas ligadas ao género textual. In: SCHOLZE, Lia; RÖSING, Tania M. K. Teorias e práticas de letramento. Brasília: Instituto Nacional de Estudos e Pesquisas Educacionais Anísio Teixeira, 2007.

RIBEIRO, Ana Elisa. Navegar sem ler, ler sem navegar e outras combinações de habilidades do leitor. Educ. rev., Belo Horizonte, v. 25, n. 3, p. 75-102, Dec. 2009. Disponível em: http://www.scielo.br/scielo.php?script=sci_arttext\&pid=S0102$46982009000300005 \&$ Ing=en\&nrm=iso. Acesso em 15 Nov. 2018.

ROJO, Roxane Helena Rodrigues. Pedagogia dos Multiletramentos: Diversidade cultural de linguagens na escola. In: ROJO, Roxane; MOURA, Eduardo (Orgs.). Multiletramentos na Escola. São Paulo: Parábola Editorial, 2012.

SOARES, Magda. Letramento: um tema em três gêneros. 3. ed. Belo Horizonte: Autêntica, 2012.

UNESC. Universidade do Extremo Sul Catarinense. Projeto Pedagógico do Curso de Administração. Criciúma, 2016. Disponível em:

http://www.unesc.net/portal/capa/index/40/5840/. Acesso em: 23 de maio 2019.

UNESC. Universidade do Extremo Sul Catarinense. Projeto Pedagógico do Curso de Direito. Criciúma, 2014. Disponível em:

http://www.unesc.net/portal/resources/official_documents/10363.pdf?1406125187. Acesso em: 23 maio 2019.

UNESC. Universidade do Extremo Sul Catarinense. Projeto Pedagógico do Curso de Engenharia Civil. Criciúma, 2017. Disponível em:

http://www.unesc.net/portal/resources/files/68/PPC_2017.pdf. Acesso em: 23 maio 2019.

UNESC. Universidade do Extremo Sul Catarinense. Projeto Pedagógico do Curso de Graduação - PPC Pedagogia - Licenciatura. Criciúma, 2015. Disponível em: http://www.unesc.net/portal/resources/files/58/PPC\%20PEDAGOGIA\%202015.pdf. Acesso em: 25 maio 2019.

UNIPLAC. Universidade do Planalto Catarinense. Administração: Disciplinas. Disponível em: https://www.uniplaclages.edu.br/graduacao/grade_disciplinas/2administracao/446-administracao-par76117-ec4-atual. Acesso em: 03 jun. 2019. 
Criar Educação, Criciúma, v. 9, nº 3, ago/dez. 2020 - PPGE - UNESC - ISSN 2317-2452

UNIPLAC. Universidade do Planalto Catarinense. Direito: Disciplinas. Disponível em: https://www.uniplaclages.edu.br/graduacao/grade_disciplinas/16-direito/453direito-mat-par76717. Acesso em: 03 jun. 2019.

UNIPLAC. Universidade do Planalto Catarinense. Engenharia Civil: Disciplinas. Disponível em: https://www.uniplaclages.edu.br/graduacao/grade_disciplinas/22engenharia-civil/457-engenharia-civil-par77217. Acesso em: 03 jun. 2019.

UNIPLAC. Universidade do Planalto Catarinense. Pedagogia: Disciplinas.

Disponível em: https://www.uniplaclages.edu.br/graduacao/grade_disciplinas/29pedagogia/467-pedagogia-par78217. Acesso em: 03 jun. 2019.

UNISUL. Universidade do Sul Catarinense. Administração: Currículo. Disponível em: http://www.unisul.br/wps/portal/home/ensino/graduacao/administracao/\#sapage-curriculo?unidade=21. Acesso em: 03 jun. 2019.

UNISUL. Universidade do Sul Catarinense. Direito: Currículo. Disponível em: http://www.unisul.br/wps/portal/home/ensino/graduacao/direito/\#sa-page-curriculo. Acesso em: 03 jun. 2019.

UNISUL. Universidade do Sul Catarinense. Engenharia Civil: Currículo. Disponível em: http://www.unisul.br/wps/portal/home/ensino/graduacao/engenharia-civil/\#sapage-curriculo?unidade=21. Acesso em: 03 jun. 2019.

UNISUL. Universidade do Sul Catarinense. Pedagogia: Currículo. Disponível em: http://www.unisul.br/wps/portal/home/ensino/graduacao/pedagogia/\#sa-pagecurriculo? unidade=21. Acesso em: 03 jun. 2019.

UNIVALI. Universidade do Vale do Itajaí. Administração: Disciplinas. Disponível em: https://www.univali.br/graduacao/administracao-

itajai/disciplinas/Paginas/default.aspx. Acesso em: 23 maio 2019.

UNIVALI. Universidade do Vale do Itajaí. Direito: Disciplinas. Disponível em: https://www.univali.br/graduacao/direito-itajai/disciplinas/Paginas/default.aspx. Acesso em: 25 maio 2019.

UNIVALI. Universidade do Vale do Itajaí. Engenharia Civil: Disciplinas. Disponível em: https://www.univali.br/graduacao/engenharia-civilitajai/disciplinas/Paginas/default.aspx. acesso em: 23 jul. 2019.

UNIVALI. Universidade do Vale do Itajaí. Pedagogia: Disciplinas. Disponível em: https://www.univali.br/graduacao/pedagogia-itajai/disciplinas/Paginas/default.aspx. Acesso em: 25 maio 2019. 
Criar Educação, Criciúma, v. 9, ํo 3, ago/dez. 2020 - PPGE - UNESC - ISSN 2317-2452

UNIVILLE. Universidade da Região de Joinville. Administração: Matriz Curricular. Disponível em:

https://www.univille.edu.br/community/novoportal/VirtualDisk.html/downloadDirect/12 49935/Administracao_2018_1.pdf. Acesso em 03 jun. 2019.

UNIVILLE. Universidade da Região de Joinville. Direito: Matriz Curricular.

Disponível em: Disponível em:

https://www.univille.edu.br/community/novoportal/VirtualDisk.html/downloadDirect/12 49945/Direito_2018_1.pdf. Acesso em: 03 jun. 2019.

UNIVILLE. Universidade da Região de Joinville. Engenharia Civil: Matriz Curricular. Disponível em:

https://www.univille.edu.br/community/novoportal/VirtualDisk.html/downloadDirect/12 49949/Engenharia_Civil_2018_1.pdf. Acesso em: 03 jun. 2019.

UNIVILLE. Universidade da Região de Joinville. Pedagogia: Matriz Curricular. Disponível em:

https://www.univille.edu.br/community/novoportal/VirtualDisk.html/downloadDirect/13 93502/Matriz_Pedagogia.pdf. Acesso em: 03 jun. 2019.

UNOCHAPECÓ. Universidade Comunitária da Região de Chapecó. Administração: Matriz Curricular. Disponível em: https://www.unochapeco.edu.br/adm. Acesso em: 03 jun. 2019.

UNOCHAPECÓ. Universidade Comunitária da Região de Chapecó. Direito: Matriz Curricular. Disponível em: https://www.unochapeco.edu.br/direito. Acesso em: 03 jun. 2019.

UNOCHAPECÓ. Universidade Comunitária da Região de Chapecó. Engenharia Civil: Matriz Curricular. Disponível em: https://www.unochapeco.edu.br/civil. Acesso em 03 jun. 2019.

UNOCHAPECÓ. Universidade Comunitária da Região de Chapecó. Pedagogia: Matriz Curricular. Disponível em: https://www.unochapeco.edu.br/pedagogia. Acesso em: 03 jun. 2019.

UNOESC. Universidade do Oeste de Santa Catarina. Administração: Disciplinas. Disponível em:

https://www.unoesc.edu.br/cursos/graduacao/administracao/disciplinas/1/600/M/50. Acesso em 03 jun. 2019.

UNOESC. Universidade do Oeste de Santa Catarina. Direito: Disciplinas. Disponível em: https://www.unoesc.edu.br/cursos/graduacao/direito/disciplinas/14/600/P/22. Acesso em: 03 jun. 2019. 


\section{CRIAR EDUCAÇÃO}

Revista do Programa de Pós-Graduação em Educação - UNESC

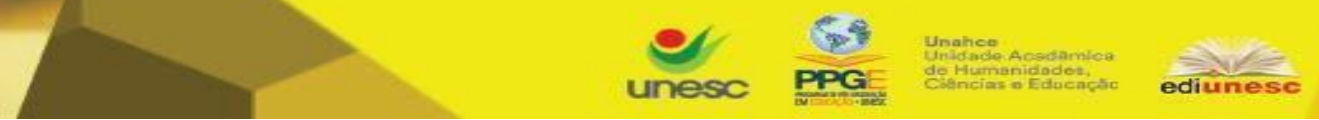

Criar Educação, Criciúma, v. 9, ํo 3, ago/dez. 2020 - PPGE - UNESC - ISSN 2317-2452

UNOESC. Universidade do Oeste de Santa Catarina. Engenharia Civil: Disciplinas. Disponível em: https://www.unoesc.edu.br/cursos/graduacao/engenhariacivil/disciplinas/20/600/P/5. Acesso em: 03 jun. 2019.

UNOESC. Universidade do Oeste de Santa Catarina. Pedagogia: Disciplinas. Disponível em:

https://www.unoesc.edu.br/cursos/graduacao/pedagogia/disciplinas/37/600/M/114. Acesso em: 03 jun. 2019.

VITÓRIA, Maria Inês Corte; CHRISTOFOLI, Maria Conceição Pillon. A escrita no Ensino Superior. Educação (UFSM), Santa Maria, p. 41-54, fev. 2013. ISSN 19846444. Disponível em: https://periodicos.ufsm.br/reveducacao/article/view/5865. Acesso em: 08 jan. 2019. 